UDC 67.400

LBC 340

\title{
THE CATEGORY OF "SOVEREIGNTY": THE GENESIS AND MODERN INTERPRETATIONS IN THE LEGAL SCIENCE
}

\author{
Sergey Yu. Chapchikov \\ South-West State University, Kursk, Russian Federation
}

Introduction: the article is devoted to the genesis, the main stages of the development and the analysis of modern interpretations of the category of "sovereignty" in the political and legal science. Purpose: to analyze the discussion of the representatives of different law schools on the role of sovereignty in the politics of modern states and the essence of this category in modern life. Methods: the methodological basis for this study is a set of scientific methods, among which the method of systemacity, the method of analysis and the comparative law method are of particular importance. Results: the analysis of the category of sovereignty is conducted; the genesis and the evolution of the concept as well as the role of sovereignty in the changing world are illustrated. Conclusions: it is found that the category of sovereignty has come a long way of development. In the course of this development, it has evolved from a narrow concept, focused on the rationale of the supreme power of the monarch in a certain area in the struggle against the feudal fragmentation and the Catholic Church, into the rich in content category of the political science and international law.

Keywords: sovereignty, the independence of a state in the international arena, the supremacy of state power within a country, power, state, globalization.

ББК 67.400

УДК 340

\section{КАТЕГОРИЯ «СУВЕРЕНИТЕТА»: ГЕНЕЗИС И СОВРЕМЕННЫЕ ТРАКТОВКИ В ЮРИДИЧЕСКОЙ НАУКЕ}

\author{
Сергей Юрьевич Чапчиков
}

Юго-Западный государственный университет, г. Курск, Российская Федерация

\begin{abstract}
Введение: статья посвящена генезису, основным этапам развития и анализу современных трактовок категории «суверенитета» в политической и юридической науках. Цель: проанализировать дискуссии представителей разных юридических школ о роли суверенитета в политике современных государств и сущности этой категории в современной жизни. Методы: методологическую основу данного исследования составляет совокупность методов научного познания, среди которых особое значение имеют метод системности, метод анализа и сравнительно-правовой метод. Результаты: проведен анализ категории «суверенитета», показаны генезис и эволюция данного понятия, место суверенитета в меняющемся мире. Выводы: установлено, что категория «суверенитета» прошла долгий путь развития. В ходе этого развития она превратилась из узкого понятия, направленного на обоснование верховной власти монарха на определенной территории в условиях борьбы с феодальной раздробленностью и католической церковью, в богатую по содержанию категорию политической науки и международного права.

그 Ключевые слова: суверенитет, независимость государства на международной арене, верховенство государственной власти внутри страны, власть, государство, глобализация.
\end{abstract}

\section{Введение}

Слово «суверенитет» имеет корни как во французском языке от «soveranité», так и в ла- тинском языке от «suprema potestas» и переводится как «высшая власть» [6].

В современной научной литературе понятие «суверенитет» часто рассматривается 
как синоним понятия «государственный суверенитет» и определяется как «независимость государства на международной арене и верховенство государственной власти внутри страны».

Однако в науке суверенитет никогда не был однозначным понятием. На протяжении нескольких столетий ведется полемика вокруг проблемы делимости суверенитета. Применительно к проблематике многосоставных политических сообществ и федеративных государств возникал вопрос о носителе и субъекте суверенитета (носителем суверенитета выступает единое государство или его составные части - штаты, земли и т. д.). Со времен Дж. Локка и Ж.-Ж. Руссо не утихают философские диспуты по поводу носителя суверенитета (народ, большинство народа и т. д.) и проблемы его субъектности.

Различные авторы на современном этапе пытаются прочертить траектории его эволюции, обосновать необходимость ограничения суверенитета государств, вводят в научный и политический оборот концепции «исчезающего», «мягкого», «многослойного» и тому подобного суверенитета. Все чаще речь идет о том, что суверенитет государств - это пережиток средневековой вестфальской системы организации международных отношений. Согласно этой точке зрения в новом, в основном демократическом, современном мире, в котором общепризнанными являются универсальные ценности, утверждающие приоритет прав и свобод человека, суверенитет становится барьером на пути их защиты и ему, следовательно, не должно быть места в практике современных международных отношений.

Такой подход к значению суверенитета формируется как прямое последствие глобализации, которая по-новому рассматривает роль основного субъекта международных отношений и мировой политики - государства, важнейшим признаком которого является суверенитет. В результате в политической науке и теории права стали складываться теории, которые провозгласили конец суверенитета, расчищая, таким образом, путь к прямому вмешательству в дела других государств в форме «гуманитарных интервенций». В 1990-е - начале 2000-х гг. это была типич- ная практика стран НАТО по свержению не угодных им правительств.

Все это вновь и вновь заставляет ученых обращаться к категории «суверенитета», изучать ее различные грани, изменение видов и сущности. Прежде всего обратимся к рассмотрению происхождения данной категории.

\section{Генезис и эволюция понятия《суверенитет»}

Понятие пришло в общественно-политическую мысль в XVI в. и было обосновано видным французским мыслителем Ж. Боденом [7]. Именно ему принадлежит определение суверенитета как «абсолютной и незыблемой власти монарха в государстве», которое он сформулировал в знаменитом труде «Шесть книг о государстве» (1576.)

При этом концепция суверенитета фактически формировалась и развивалась вместе с идеей современного (национального) государства. Согласно широко распространившимся и закрепленным в международном праве после Вестфальского мира (1648) представлениям каждое государство должно было обладать внутренним и внешним суверенитетом. Внутренний суверенитет непосредственно связан с ключевым для мира политики понятием власти. Значимость внутреннего суверенитета состоит прежде всего в том, что государству принадлежит верховная власть над всей территорией, на которую распространяется его юрисдикция. Внешний суверенитет заключается в свободе поведения государств на международной арене в процессе реализации своих интересов и целей и при отсутствии некой «вышестоящей» силы над суверенным государством. Отсюда вытекает краеугольный принцип современного международного права - суверенного равенства государств.

В Новое время Томас Гоббс (1588-1679), развивая теорию суверенитета, попытался найти ответ на вопрос об источнике суверенитета. Он одним из первых сформулировал на этот счет две важнейшие идеи. Первая объясняла возникновение государства как результат заключения общественного договора, прекратившего войну всех против всех. Вторая замечательная догадка Гоббса зак- 
С.Ю. Чапчиков. Категория «суверенитета»: генезис и современные трактовки в юридической науке

лючалась в обосновании необходимости в государственном устройстве «народного представительства» как механизма реализации власти народа.

По Гоббсу общественный договор, обеспечивая «объединение каждого с каждым», превращает народную массу, толпу в организованное общество и создает механизм управления общественными делами - государство, воля которого в силу соглашения многих людей считается за волю их всех. Это и дает государству право «распоряжаться силами и способностями отдельных членов в интересах общего мира».

Современные критики Т. Гоббса, соглашаясь с ним, что никакие договоры не будут соблюдаться, пока нет гарантирующего их государства, считали, тем не менее, идею народного представительства нереализуемой теоретической абстракцией [9].

Дальнейшее развитие идей суверенитета связано с трудами таких выдающихся мыслителей, как английский юрист Джон Локк (1634-1704), французский философ Жан-Жак Pуссо (1712-1778).

Они дополнили идею Гоббса о народе как источнике суверенитета гипотезой, согласно которой власть возникает с формированием гражданского общества, то есть всей совокупности граждан, которые объединились для выражения их общей воли, и избранием подотчетного народу представительного и законодательного органа.

По мнению Руссо, народный суверенитет - это принцип осуществления общей воли. Представляет практический интерес и идея Руссо о том, что есть «общая воля» и «воля всех». Общая воля выражает общие интересы, в то время как воля всех есть сумма волеизъявления частных лиц. Существенно и содержательное отличие общей воли от воли всех. По мнению Руссо, источником законов может быть только общая воля, которая должна быть и принципом управления, и мерилом справедливости.

Руссо принадлежит и часто цитируемая мысль о том, что «все люди рождаются свободными и ни один человек не имеет власти над другим от природы».

Так как сила не может порождать право, считал Руссо, то единственным законным основанием для установления авторитета власти является договор. Признавая общественный договор, каждый человек вместе с другими людьми подчиняет себя власти, поскольку в результате договора создается публичное лицо государства, выражающее общую волю народа. Власть, управляемая общей волей, пишет Руссо, называется суверенитетом [8].

Суверенитет как народное волеизъявление не может быть ограничен и разделен. Философ был убежден, что народ не может отказаться от своего права на решение собственной судьбы и самоуправления, а правительство «лишь временный агент суверенного народа». Совпадая с идеями Локка, эта мысль Руссо расходится с идеями других просветителей в значении суверенитета для утверждения различных ветвей власти. Локк исходил из того, что народ вручает органам управления всю власть: исполнительную, законодательную и судебную. Руссо же имел на этот счет совсем другой взгляд, выступая против передачи парламенту даже законодательной власти. По мнению Руссо, суверенность выражается общей волей народа и не нуждается в представительских учреждениях.

Во французской Декларации прав человека и гражданина источником любого суверенитета провозглашался именно народ, или нация. По мнению исследователя этой проблемы А.А. Сергунина, «такое позитивное развитие теории в действительности вело ее в тупик, поскольку народ все еще оставался только эмпирическим феноменом» [9]. Народ видели на баррикадах революции, но не понимали его связи с историческим и культурным развитием общества.

Выдающимся теоретиком права своего времени был Шарль-Луи Монтескье (16891755). Своеобразие его взглядов на суверенитет, сформулированное в работе «О духе законов» (1748), заключалось в идее, согласно которой народ является сувереном только в ходе выборов, на которых он выражает свою волю. Исходя из этой логики Монтескье считал основными законами законы, определяющие правила голосования. При этом основным законом демократии согласно ученому является закон, устанавливающий, что законодательная власть принадлежит только народу. 


\section{ТЕОРИЯ И ПРАКТИКА ГОСУДАРСТВЕННО-ПРАВОВОГО РАЗВИТИЯ}

Суммируя взгляды представителей эпохи буржуазных революций о суверенитете, можно выделить несколько основных положений:

Во-первых, суверенитет - это абсолютная, неотчуждаемая и неделимая власть народа, которая регулируется его общей волей.

Во-вторых, сувереном всегда является народ. Это в свою очередь предполагает, что единственно правильная форма организации государственной власти - демократия, устанавливаемая договором.

В-третьих, если происходит присвоение народного суверенитета каким-либо частным лицом или группой лиц, то общественный договор разрывается и все лица возвращаются в состояние своей естественной свободы. Поскольку, как считал, например, Джон Локк, договор не означает полного отказа народа от своих прав, за ним остается право вернуть себе отданные права, если власть нарушает первоначальный договор.

Анализ историографии проблемы государственного суверенитета показывает, что в политической и юридической науке сложилось как большое количество различных определений этого понятия, так и разнообразие представлений о его содержании. Г. Еллинек, например, считал, что «существо государственного суверенитета проявляется в способности государства к исключительному правовому самоопределению», и выделял несколько граней этой способности:

Во-первых, «совершенно свободно нормировать содержание своей компетенции в пределах установленных или признанных им самим правовых границах» [4].

Во-вторых, правовое самоопределение государства проявляется в том, что «государственная власть не знает над собой никакой высшей власти; она является независимой и верховной властью». Отсутствие другой, высшей над государством власти, по мнению Еллинека, проявляется преимущественно вовне, в сношениях суверенного государства с другими державами. Что касается верховного и независимого характера государственной власти, то эти качества государства проявляются «во внутренних отношениях с входящими в состав государства лицами» [4].

\section{Место суверенитета \\ в меняющемся мире}

Важнейший принцип суверенитета, гарантирующий невмешательство государств в дела друг друга, практически не подвергался сомнению на протяжении XIX-XX веков. Ситуация стала меняться одновременно с процессом глобализации. Вместе с глобализацией стали появляться новые субъекты мировой политики, которые стали составлять серьезную конкуренцию государству. Важнейшую роль в борьбе за перераспределение ресурсов и власти стали играть транснациональные корпорации, которым идея невмешательства в государственные дела даже других стран стала мешать действовать в борьбе за прибыль и бесконтрольность со стороны власти.

Неудивительно, что синхронно с этим процессом появились и работы ученых, которые стремились доказать, что «традиционные концепции суверенитета не способны выразить сложность современных международных отношений» [10]. Кроме транснациональных корпораций с критикой роли суверенитета выступили некоторые массовые движения, оказывающие определяющее воздействие на формирование идентичности значительных групп населения, транснациональные политические сети, все более явно воздействующие на формирование международной повестки дня, и иные формы социальной и политической организации. Определенное влияние на отношение к суверенитету стала оказывать тенденция усиления взаимозависимости государств в условиях глобализации. В этой ситуации на первый план вышла задача эффективной «включенности» в международное разделение труда.

Суверенитет стал рассматриваться не как способ защиты от вторжения, а как барьер от угрожающего «невторжения (в терминологии У. Бека [3]) инвесторов или угроза их ухода из той или иной страны.

Возникновение новых типов угроз и новых видов конфликтов ведет к размыванию ряда ключевых понятий и принципов организации системы международных отношений, в том числе к попыткам переформулировать проблематику государственного суверенитета. 
С.Ю. Чапчиков. Категория «суверенитета»: генезис и современные трактовки в юридической науке

\section{Перед лицом новых вызовов XXI века}

Процессы глобализации в XXI в., дополненные растущим дефицитом ресурсов, обострением конкуренции ценностей, образов жизни, создают новые опасности для суверенитета многих стран. Они связаны с лозунгами необходимости «интернационализации дефицитных ресурсов культурных интервенций, защиты прав человека, борьбы с авторитарными режимами» и т. д. Развертывание информационной войны идет под лозунгами необходимости противостояния гибридной войне, агрессивной пропаганде, борьбы с кибератаками, глобальными экологическими катастрофами.

Категория «суверенитета» в этой ситуации оказалась в центре борьбы различных идеологических течений: неореализма и неолиберализма, глобализма, постмодернизма, социального конструктивизма, феминизма и других школ теории международных отношений. Огрубляя характер этой борьбы, можно сказать, что речь идет о борьбе сторонников решающей роли государств в международных отношениях с представителями течений, отстаивающих идею о снижении роли государства в мировой политике и росте значимости транснациональных межправительственных и неправительственных институтов, «сетевых структур и т. д. Представители этой группы утверждают, что суверенитет в современном мире - это миф, опасная утопия, маскирующая корыстные интересы элиты [5].

Все это позволяет высказать предположение, что для мировой политики будущего стремление к укреплению суверенитета, защите своих национальных интересов столкнется с растущим противодействием сил, настаивающих на его ограничении, причем эти тенденции будут воплощаться в конкретной политике государств, укрепляющих свой суверенитет за счет суверенитета других. В рамках интерпретаций суверенитета XXI в., вероятно, будут скорректированы представления о пределах автономии суверенных государств в выборе средств при решении тех или иных внутриполитических проблем. В контексте международных отношений предметом дебатов станут возможности применения принудительных мер воздействия на своих оппонентов, характер взаимодействия межгосудар- ственного и транснационального уровней мировой политики, механизмы глобального управления.

Однако суверенитет никуда не исчезнет даже в столь долгосрочной перспективе, как столетие человеческой истории. Сегодня в общественной жизни ничего не свидетельствует о том, что государства перестанут быть главными субъектами на международной арене. Более того, в книге «Воображаемые сообщества» («Imagined Communities») Б. Андерсон обращает наше внимание на такой фактор сохранения в будущем роли государства, как национализм. По его мнению, «национализм обладает магической мобилизующей силой и одновременно значительной исторической инерцией». При всей масштабности грядущих перемен «абстрактное понятие суверенитета для многих миллиардов людей и многих политиков в самых разных уголках нашей планеты останется своего рода путеводной звездой в мире политики. И это вовсе не будет означать, что они встали на “неправильную сторону" истории» [1].

\section{Выводы}

Итак, категория «суверенитета» прошла долгий путь развития, в ходе которого она превратилась из узкого понятия, направленного на обоснование верховной власти монарха на определенной территории в условиях борьбы с феодальной раздробленностью и католической церковью, в богатую по содержанию категорию политической науки и международного права. На современном этапе ученые всех направлений общественной мысли считают суверенитет одной из основных категорий современной науки.

\section{СПИСОК ЛИТЕРАТУРЫ}

1. Андерсон, Б. Воображаемые сообщества. Размышления об истоках и распространении национализма / Б. Андерсон. - М. : КАНОН-пресс-Ц : Кучково поле, 2001. - 288 с.

2. Антология мировой философии : в 4 т. М. : Мысль, 1970.

3. Бек, У. Власть и ее оппоненты в эпоху глобализма. Новая всемирно-политическая экономия / У. Бек. - М. : Прогресс-Традиция, 2007. - 464 с. 


\section{ТЕОРИЯ И ПРАКТИКА ГОСУДАРСТВЕННО-ПРАВОВОГО РАЗВИТИЯ}

4. Еллинек, Г. Общее учение о государстве / Г. Еллинек. - Спб. : Н. К. Мартынов, 1908. - 626 с.

5. Иванов, В. Государство и суверенитет. Спор о суверенитете / В. Иванов // Русский журнал. 2009. - 28 сент. - Электрон. текстовые дан. - Режим доступа: http://www.russ.ru/Mirovaya-povestka/ Gosudarstvo-i-suverenitet. - Загл. с экрана.

6. Мише, П. Суверенитеты в неустойчивой среде / П. Мише // Коммунист. - 1991. - № 13. С. 83-90. - Электрон. текстовые дан. - Режим доступа: http://www.postindustrial.ru/articl3.shtml? article=134\&type=3. - Загл. с экрана.

7. Политология. Словарь-справочник / под ред. М. А. Василика, М. С. Вершинина [и др.]. - М. : Гардарики, 2001.-328 с.

8. Руссо, Ж.-Ж. Избранное / Ж.-Ж. Руссо. М. : Детская литература, 1976. - 187 с.

9. Сергунин, А. А. Суверенитет: эволюция концепта / А. А. Сергунин. - Электрон. текстовые дан. - Режим доступа: http://www.politex.info/ content/view/756/. - Загл. с экрана.

10. Slaughter, A.-M. A new world order / A.-M. Slaughter. - Princeton ; Oxford : Princeton University Press, 2004. - 341 p.

\section{REFERENCES}

1. Anderson B. Voobrazhaemye soobshchestva. Razmyshleniya ob istokakh i rasprostranenii natsionalizma [Imaginary Communities. Reflections on the Origins and Spread of Nationalism]. Moscow, KANON-press-Ts Publ.; Kuchkovo pole Publ., 2001. $288 \mathrm{p}$.
2. Antologiya mirovoy filosofii: $v 4 t$. [Anthology of World Philosophy: in 4 vols.]. Moscow, Mysl Publ., 1970.

3. Bek U. Vlast i ee opponenty $v$ epokhu globalizma. Novaya vsemirno-politicheskaya ekonomiya [Power and Its Opponents in the Era of Globalism. New World-Political Economy]. Moscow, Progress-Traditsiya Publ., 2007. 464 p.

4. Ellinek G. Obshchee uchenie o gosudarstve [General Doctrine on State]. Saint Petersburg, N. K. Martynov Publ., 1908. 626 p.

5. Ivanov V. Gosudarstvo i suverenitet. Spor o suverenitete [State and Sovereignty. The Dispute over Sovereignty]. Russkiy zhurnal, 2009, Sept. 28. Available at: http://www.russ.ru/Mirovaya-povestka/ Gosudarstvo-i-suverenitet.

6. Mishe P. Suverenitety v neustoychivoy srede [Sovereignties in an Unstable Environment]. Kommunist, 1991, no. 13, pp. 83-90. Available at: http:// www.postindustrial.ru/articl3. shtml article $=134 \&$ type $=3$.

7. Vasilik M.A., Vershinin M.S., et al. Politologiya. Slovar-spravochnik [Political Science. Dictionary-Reference Book]. Moscow, Gardariki Publ., 2001. 328 p.

8. Russo Zh.-Zh. Izbrannoe [The Selected Works]. Moscow, Detskaya literatura Publ., 1976. 187 p.

9. Sergunin A.A. Suverenitet: evolyutsiya kontsepta [Sovereignty: Evolution of the Concept]. Available at: http://www.politex.info/content/view/756/.

10. Slaughter A.-M. A New World Order. Princeton; Oxford, Princeton University Press, 2004. $341 \mathrm{p}$.

\section{Information About the Author}

Sergey Yu. Chapchikov, Candidate of Juridical Sciences, South-West State University, Law Enforcement Officer, 50 let Oktyabrya St., 94, 305040 Kursk, Russian Federation, tgpKSTU@yandex.ru.

\section{Информация об авторе}

Сергей Юрьевич Чапчиков, кандидат юридических наук, Юго-Западный государственный университет, сотрудник правоохранительных органов, ул. 50 лет Октября, 94, 305040 г. Курск, Российская Федерация, tgpKSTU@yandex.ru. 